\title{
COULD THE VIDEO AD'S NARRATIVE STRUCTURE ENGAGE STUDENTS IN CLASSROM CONTEXT?
}

\author{
Sónia Ferreira ${ }^{1 *}$, Sara Santos ${ }^{2}$, Pedro Espírito Santo ${ }^{3}$ \\ ${ }^{1}$ Prof. Dr., Center for Studies in Education and Innovation, School of Education, Polytechnic of \\ Viseu, PORTUGAL, sonia.ferreira@esev.ipv.pt \\ ${ }^{2}$ Prof. Dr., School of Education, Polytechnic of Viseu, PORTUGAL, ssantos@esev.ipv.pt \\ ${ }^{3}$ Prof. Dr., School of Technology and Management of Oliveira do Hospital, Polytechnic of Coimbra, \\ PORTUGAL, pedro.santo@estgoh.ipc.pt
}

\begin{abstract}
It is recognized that teachers have sought to innovate their methods of presenting content and, today, they have at their disposal a variety of support resources that did not have before. These potentialities have changed the way classes are taught today and the dynamics are, in most cases, different from what existed a few decades ago. Among the resources available for teaching, exhibition of videos in the classroom seems to have very relevant effects, both on students' learning and on their greater involvement in activities. However, this is not always the case and the videos presented by teachers do not have the desired effects on students.
\end{abstract}

Thus, based on the assumption that greater immersion in video activates positive behaviors in classrooms, this study seeks to analyze, through a conceptual model, the antecedents of "Narrative Transportation" (immersion in video).

In this sense, a video was presented to 107 students from a degree in Advertising and Public Relations, whose narrative is based on fun. After the presentation of the video, data was collected through the application of a questionnaire.

Through a causal relationship model, the research work reveals that, in addition to the structure of the video narrative (Narrative Structure), the variable "Joy" (Fun) acts as one of the antecedents of "Narrative Transportation".

These results thus suggest to teachers that the presentation of videos in the classroom, with narratives that involve fun and with clear structures, has benefits in immersing students in the content and narratives presented and in the involvement in the classroom.

Keywords: Narrative transportation, Narrative structure, Joy, Video ad, Education

\section{INTRODUTION}

Nowadays, people access information mainly through the media. These means assume an important role in society and allow access to information quickly and steadily. Also for students, access to information is mainly through the media, as mentioned by Buckingham (2003) "to become an active participant in public life necessarily involves making use of the modern media" (p. 5).

Advertising influences buying decisions (Rajagopal, 2006) not only for adults but also for young people and it 
also influences children. So, it is important for people to learn about advertising and to select information in mass media (Stuckey, Heering, Mamlok-Naaman, Hofstein, \& Eilks, 2015).

In the media, advertising plays an important role, since people are exposed daily (in 2006) to more than 5000 ads (Hartnett, 2006). Therefore, the critical analysis of advertising and rational decisions about it are indispensable to citizens (Belova, Rundgren \& Eilks, 2015).

It is increasingly important to learn how to make the best use of the media and interpret the information conveyed (media literacy) to understand the messages transmitted and select them (Buckingham, 2003), particularly regarding advertising.

\section{ADVERTISING}

\subsection{Advertising in Classroom}

Advertising has a big impact on people's behavior and especially young people, for example, in the area of food consumption (Villani, 2001). Also, in education, it is important to encourage critical and responsible evaluation in relation to advertising (Brucks, Armstrong, \& Goldberg, 1988).

Teachers began to use advertising materials in classes in order to stimulate students' interest, motivation and critical skills, particularly in language classes (Martin, 2012). Advertising using text and video, in a brief and visually attractive way, allows in addition to brand recall and recognition, effective learning of a second language, often with humor and cultural references (Etienne \& Vanbaelen, 2006; Martin, 2006).

When teaching strategies using advertising are used, students improve their critical advertising skills by reducing their susceptibility to advertising (Rozendaal, Buijzen \& Valkenburg, 2012). When evaluating advertising messages, students learn public influence and persuasion techniques (Belova \& Eilks, 2016) as well as they develop critical thinking skills (Belova et al., 2015).

On the other hand, the images and visual communication of the advertisements allow to deepen the messages and reflect critically on them (Freedman \& Wood, 1999).

Scheibe and Rogow (2012) analyse advertising in relation to image of science in science classroom and this methodology can also stimuli students to participate in societal debates (Belova \& Eilks, 2014).

In science education, Belova \& Eilks (2014) evidences that advertising can motivate students to learn, contextualize science-related tasks, stimulate critical thinking and learn about the role of science and technology.

With the advance in internet, also in education there was modifications, incorporating web technologies in teaching (King, 2002) and a variety of formats such as video, text, hyperlink, etc (McCurry, 2002).

Although there is an extensive literature on the effects of advertising on children, it is necessary to deepen the use of advertising in the classroom so that students (youngers) identify the purpose of the message, points of view, target audience and persuasive technique used (Buckingham, 2003) as well as create advertising in print, visual, video, and multimedia formats.

\subsection{Transportation, Structure, and Joy}

Initially proposed by Green, in 1996, the transportations concept defines the transportation process for a fictional reality created in a story. To confirm this, individuals need to highlight the effects that these narratives have on their beliefs, attitudes and behaviors (Green \& Clark, 2012).

According to Green and Brock, it is a convergent process of integration of attention, imagination and feelings (Green \& Brock, 2000) in which all mental systems are directed towards the narrative. When transported to the fictional world created by an author, the individual loses access to the real and can experience the emotions evoked by the story (Green \& Brock, 2000). This is because people do not always separate information into fiction / nonfiction because they do not know or do not remember that the information is fictional.

The growing interest in research aimed at communicating products and services based on narrative reveals the importance of implementing approaches that provoke attitudes in the recipients. Knowing that the receptivity to messages differs from individual to individual, they are increasingly willing to be transported to the advertising narrative (Brechman \& Purvis, 2015).

In addition, Escalas (2007) states that narrative ads are not openly persuasive, but of an affective nature allowing the consumer to be taken unconsciously. Facts, numbers and arguments tend to alienate the individual and promote a distant attitude (Gottschal, 2012). Dessart's study reveals that "the immersion 
experience can have positive effects on the attitude if the positive emotion of joy is induced by the experience of being transported by a narrative ad". (2018, p. 301). Structurally, the narratives are worked to bet on a plot with incidents and surprises, on characters to whom conflicts and events happen and at a climax moment where the resolution of the story is presented (van Laer et al. 2014) and the conflict finally resolved. Still, and according to Dessart (2018), the commercial strategy of the ads should aim to balance the elements of the narrative with the facts.

The symbiosis between the structure of the narrative and the elements of the story creates a powerful tool for transmitting information (Brechman \& Purvis, 2015) and, when created effectively, allows for more favorable cognitive responses, warm feelings and positive attitudes of the narrative ad, when compared to argument advertising (Chang, 2009). According to Bruner (1990, as mentioned in Brechman \& Purvis, 2015), the traditional definitions propose that the narratives present a chronology - organization of events with a temporal dimension with beginning, middle and end - and causality, that is, structuring the elements of the story of organized way that allows for causal inference.

In addition to including emotional appeals, narratives are endowed with structural elements that "provide context, usually establishing an environment that has physical, social and temporal components, and the story is further enhanced with the use of images to guide consumers' imaginations, involvement or immersion in the story"(Brechman \& Purvis 2015, p. 367).

Regardless of the medium, television, cinema, literature or video game, the objective of any narrative is to try to transport the audience, making them return to experiences, obtain perceptions and emotions and draw conclusions about the story (Escalas, 2007).

\section{RESEARCH HYPOTHESES}

The description of a concept in the form of a story can facilitate the processing of new information and can help a faster understanding of new information (Schweitzer \& Van den Hende, 2017). The narrative stimulates the connection to the presented contents (Hosany, Buzova, \& Sanz-Blas, 2020) and the evidence shows that the characteristics of the narrative such as the humor and the joy that the video conveys influences the message processing (Lien \& Chen, 2013). Ryu, Lehto, Gordon, and Fu (2019) emphasize that the processing of the message by the individuals allows them to understand more complex stories or to understand the concepts more quickly.

In this context, our study conceptualizes the narrative structure as the understanding of the main message and the perception that the video has a beginning, middle and end. Thus, we consider that the joy of the video for each of the students allows a better assessment of the narrative presented. In this way, our study will test the following research hypothesis.

\section{$\mathrm{H} 1$ : The joy in the narrative positively influences the perceived structure of the narrative}

The concept of narrative transportation is based on immersion in a hypothetical world that, the individual allows himself to be taken, for the scenes of the presented narrative (Kim, Lloyd \& Cervellon, 2016; Lien \& Chen, 2013). Green and Brock (2000) emphasize that immersion in the narrative is carried out through a mental process that combines the images and feelings of each person at the moment. The joy in the narratives causes a set of positive feelings that, Moyer-Gusé and Nabi (2010) refer to the importance of the emotional connection that is created with the characters. In this sense, we consider that the transportation to the narrative is influenced by the joy of the narrative. In this context, we present the following research hypothesis:

$\mathrm{H} 2$ : The joy in the narrative positively influences narrative transportation

The depth of transportation for the narrative depends on the ad being displayed, so stories with a higher quality and better structure will trigger a greater likelihood to transportation individuals to the narrative (Schreiner, Appel, Isberner \& Richter, 2018). In this context, we present the following research hypothesis:

H3: The narrative structure has positive effects on narrative transportation

A narrative story must include an attractive structure that allows connections with its elements. The plot presented in the narrative develops affective responses by individuals (Ryu et al., 2019) even more so when the narrative presents cheerful images (Lee, Jeong \& Oh, 2018). It is these affective responses that transport individuals to a new world, immersing themselves in the narrative more deeply. Thus, we consider it pertinent for our study to test the following research hypothesis:

$\mathrm{H} 4$ : The narrative structure plays a mediating role in the joyful effects of the narrative in narrative transportation 


\section{METHODOLOGY}

The research hypotheses served as a basis for the development of the methodology and our empirical study was based on the proposed conceptual model. In this sense, we applied a questionnaire to students of the degree in Advertising and Public Relations, in the classroom, using scales previously used by other authors and adapted to the context under study. The questionnaire consisted of Likert scales whose answers varied between 1 (strongly disagree) and 5 (strongly agree). The items used for the questionnaire are shown in table 1.

Table 1. Questionnaire items

\begin{tabular}{|c|c|c|}
\hline Concept & Item & code \\
\hline Narrative transportation & While watching the ad I didn't think of anything else. & NST1 \\
\hline \multirow[t]{2}{*}{ (Dessart, 2018) } & This ad appealed to me from beginning to end. & NST2 \\
\hline & $\begin{array}{c}\text { While watching the ad, I imagined myself in the scenes of the } \\
\text { video. }\end{array}$ & NST3 \\
\hline Narrative Ad Structure & The structure of this video has a beginning, middle and end. & NTR1 \\
\hline \multirow[t]{2}{*}{ (Dessart, 2018) } & I understood the evolution of the character. & NTR2 \\
\hline & I understood the main message. & NTR3 \\
\hline Joy & The video is joyfull. & JOY1 \\
\hline \multirow[t]{3}{*}{ (Dessart, 2018) } & I find the advertisement pleasant. & JOY2 \\
\hline & The ad is fun. & JOY3 \\
\hline & I was delighted with the ad. & JOY4 \\
\hline
\end{tabular}

To collect data, we presented a narrative ad that is available on Youtube at https://www.youtube.com/watch?v=LZAAARvVsxl. After the students watch the ad they were asked to answer the questionnaire whose items were presented in table 1. The responses were collected anonymously, of which we considered valid, 107 responses whose characterization is shown in table 2. From the sample, it appears that the majority of respondents are female $(\mathrm{N}=67 ; 62,6 \%)$ and $86,9 \%(\mathrm{~N}=93)$ are between 20 and 29 years old.

Table 2 - Sample characterization

\begin{tabular}{|c|c|c|c|}
\hline Variable & Category & $\mathrm{N}$ & $\%$ \\
\hline Gender & Female & 67 & 62,6 \\
\hline & Male & 40 & 37,4 \\
\hline Age & $<20$ years & 10 & 9,3 \\
\hline & 20 to 29 years & 93 & 86,9 \\
\hline & 30 to 39 years & 1 & 0,9 \\
\hline & 40 to 49 years & 2 & 1,9 \\
\hline & Missing & 1 & 0,9 \\
\hline & Total & 107 & 100,0 \\
\hline
\end{tabular}

The data analysis we applied was the multivariate analysis using Partial Least Squares - Path model estimation since it allows determining causal relationships between multiple constructs (Hair, Hult, Ringle, \& Sarstedt, 2016; Hair, Risher, Sarstedt \& Ringle, 2018). For our study, we used the SMARTPLS 3.2.8 software and developed the analysis in two phases: analysis of the measurement model and analysis of the path model.

In a previous analysis of the data, we diagnosed the existence of multicollinearity between the items by the criterion $\mathrm{VIF}<5$ (Hair et al., 2016; Maroco, 2014). Since, due to VIF values, multicollinearity is not supposed 
to exist, we begin the analysis of the measurement model.

The result obtained for the measurement model is shown in table 3.

Table 3 - Measurement model analysis $\left({ }^{* *} p<0,01 ;{ }^{*} p<0,05\right)$

\begin{tabular}{|c|c|c|c|c|c|c|c|}
\hline Latent Variable & Item & Mean & $\begin{array}{c}\text { Standard } \\
\text { deviation }\end{array}$ & $\boldsymbol{\lambda}$ & $\boldsymbol{t}$ value & AVE & C.R. \\
\hline Narrative Structure & & & & & & 0.581 & 0.847 \\
\hline (NST) & NST1 & 3,86 & 0,946 & 0.741 & $17,855^{\star *}$ & & \\
\hline & NST2 & 4,29 & 0,752 & 0.839 & $19,701^{* *}$ & & \\
\hline & NST3 & 4,24 & 0,799 & 0.765 & $13,874^{\star *}$ & & \\
\hline NST4 & 4,53 & 0,705 & 0.700 & $8,398^{* *}$ & & \\
\hline $\begin{array}{c}\text { Narrative } \\
\text { Transportation }\end{array}$ & & & & & & 0.803 & 0.891 \\
\hline (NTR) & NTR1 & 3,78 & 1,127 & 0.879 & $23,463^{\star *}$ & & \\
\hline & NTR2 & 4,04 & 1,018 & 0.913 & $45,029^{\star *}$ & & \\
\hline & NTR3 & 2,44 & 1,283 & \multicolumn{2}{|c|}{ DELETED } & & \\
\hline Joy & & & & & & 0.744 & 0.920 \\
\hline (Joy) & JOY1 & 4,36 & 0,782 & 0.855 & $24,625^{\star *}$ & & \\
\hline & JOY2 & 4,24 & 0,846 & 0.914 & $47,069^{* *}$ & & \\
\hline & JOY3 & 4,26 & 0,876 & 0.891 & $37,086^{* *}$ & & \\
\hline & JOY4 & 3,35 & 1,033 & 0.784 & $17,443^{* *}$ & & \\
\hline
\end{tabular}

From the results obtained and presented in table 3 , we verified that the standardized coefficients $(\lambda)$ are greater than or equal to $0,7(p<0,01)$ and have significant $t$ values for $p<0.01$. We also found that the value of the average variance extracted (AVE) of the concepts is greater than 0.5 and the composite reliability (C.R.) is greater than 0.7 (Hair et al., 2018), which leads us to consider that the concepts have item reliability and convergent validity (Hair, Black, Babin, \& Anderson, 2010).

In order to verify the discriminating validity between the items, we used the criteria of Fornell and Larcker (1981) (table 4) and the Heterotrait-Monotrait ratio (HTMT) by Henseler, Ringle, and Sarstedt (2015) (table 5).

Table 4 - Discriminant Validity: criteria for Fornell and Larcker (1981)

\begin{tabular}{|c|c|c|c|}
\hline & JOY & NST & NTR \\
\hline JOY & 0,862 & & \\
\hline NST & 0,662 & 0,762 & \\
\hline NTR & 0,591 & 0,617 & 0,896 \\
\hline
\end{tabular}

Table 5 - Discriminant Validity: Henseler's et al. (2015) HTMT Ratio

\begin{tabular}{|c|c|c|c|}
\hline & JOY & NST & NTR \\
\hline JOY & & & \\
\hline NST & 0,766 & & \\
\hline NTR & 0,714 & 0,791 & \\
\hline
\end{tabular}

Table 4 shows that the values of the square root of the average variance extracted (AVE) presented diagonally are superior to the correlations between the concepts. From table 5 we can see that the HTMT ratio is less than 0.9 as recommended by Henseler et al. (2015). We conclude that the concepts have discriminant validity.

The second phase of our study aimed to test the hypotheses under study by testing hypotheses through the analysis of structural coefficients. To estimate the structural coefficients, we used the bootstrapping resampling method with 5000 subsamples. We present the results in table 6. 
Table 6 Structural coefficients present in the model

\begin{tabular}{|c|c|c|c|c|c|}
\hline Hip & $\boldsymbol{\beta}$ & $\boldsymbol{t}$ values & $\boldsymbol{p}$ values & $\begin{array}{c}95 \% \text { confidence } \\
\text { Interval }\end{array}$ & \\
\hline H1: JOY $\rightarrow$ NST & 0,662 & 11,737 & 0,000 & {$[0,554 \ldots 0,773]$} & Confirmed \\
\hline H2: JOY $\rightarrow$ NTR & 0,325 & 3,409 & 0,001 & {$[0,160 . .0,528]$} & Confirmed \\
\hline H4: NST $\rightarrow$ NTR & 0,402 & 4,067 & 0,000 & {$[0,195 \ldots 0,580]$} & Confirmed \\
\hline H4: JOY $\rightarrow$ NST $\rightarrow$ NTR & 0,266 & 4,217 & 0,000 & {$[0,138 . .0,388]$} & Confirmed \\
\hline
\end{tabular}

The conceptual model studied explains in $43.3 \%$ the variation of narrative transportation $\left(R^{2}=0,433\right)$ and the hypotheses under study were confirmed by our empirical study.

\section{CONCLUSION}

Our study tried to test the effects of the joy present in the narrative in the transport to a fictional world presented by the narrative.

First, our study analyzed the effects of the joy in narrative and in its structure. We conclude that these effects are positive and significant $(\beta=0.662 ; t=11,737 ; \mathrm{p}<0.01)$. Our research supports the $\mathrm{H} 1$ hypothesis under study. The joy present in the narrative positively influences $(\beta=0.325 ; t=3.409 ; p<0.01)$ transportation in the imaginary world of the narrative, confirming hypothesis $\mathrm{H} 2$. From the confirmation of these two hypotheses, we confirm that the joy in the narrative is an important variable for the students to better understand its structure and the immersion in the scenes in the video is deeper.

Our study also found that the structure of the narrative influences immersion in the video scenes. The H3 hypothesis $(\beta=0.402 ; t=4.067 ; p<0.01$ ) has been confirmed.

Finally, we test the mediating effects of the narrative structure on the relationship between joy in the video and transportation in the world of narrative. Our study supports this $\mathrm{H} 4(\beta=0.266 ; t=4,217 ; \mathrm{p}<0.01)$.

Vaughn, Childs, Maschinski, Paul Niño, and Ellsworth (2010) refer that the transportation to the narrative is a process of emotional and cognitive immersion that occurs in a narrative, during which the individual loses the notion of the real world around him. These authors state that immersion is a highly engaged state of absorption that people devote most of their attention to building emotional and cognitive meaning from the events of history. In this context, our study allows us to conclude that the joy present in the videos presented to students in the classroom allows students to be transported to the hypothetical world of the narrative. This relationship takes place through direct effects and also through the mediating role of the structure of the narrative. We conclude then that students will enter a process of greater engagement in classes taught using videos that transmit content and that are presented with joy.

Thus, as practical recommendations, our study proves to be important to emphasize that, in teaching, it is important to present some content through joyful videos with a well-structured narrative in order to be able to absorb students in a process of emotional relationship with teachers and with classes.

We believe that our study has a contribution to teaching in social sciences, however, there are some lines of research that we consider important for scientific study. In this field, we consider it relevant to study information processing in several types of narrative, such as informative or real narratives. We also consider it relevant to analyze the impact of the narrative voice of a video and the effects of the strength of the arguments on the emotional connection to the video and the content presented.

\section{ACKNOWLEDGMENT}

This work is financed by National Funds through FCT - Foundation for Science and Technology, I.P., under the project Ref ${ }^{a}$ UIDB / 05507/2020. We would also like to thank the Center for Studies in Education and Innovation (CI \& DEI) and the Polytechnic of Viseu for their support. 


\section{REFERENCE LIST}

Belova, N.; Rundgren, S. C. \& Eilks, I. (2015). Advertising and science education: a multi-perspective review of the literature. Studies in Science Education, 51 (2),169-200, doi:10.1080/03057267.2015.1049444

Belova, N. \& Eilks, I. (2014). Promoting societal-oriented communication and decision-making skills by learning about advertising in science education. Centre for Educational Policy Studies Journal, 4(1), $32-49$.

Belova, N. \& Eilks, I. (2016). German Teachers' Views on Promoting Scientific Media Literacy Using Advertising in the Science Classroom. International Journal of Science and Mathematics Education, 14, 1233-1254. doi: 10.1007/s10763-015-9650-5

Brechman, J. M. \& Purvis, S. C. (2015). Narrative, transportation and advertising. International Journal of Advertising, 34(2), 366-381. doi: https://doi.org/10.1080/02650487.2014.994803

Brucks, M., Armstrong, G. M., \& Goldberg, M. E. (1988). Children's use of cognitive defenses against television advertising: A cognitive response approach. Journal of Consumer Research, 14, 471-482. doi: https://doi.org/10.1086/209129

Buckingham, D. (2003). Media education: Literacy, learning and contemporary culture. Cambridge, United Kingdom: Polity

Chang, C. (2009). "Being Hooked" by editorial content: The implications for processing narrative advertising. Journal of Advertising, 38(1), 21-34. doi: https://doi.org/10.2753/JOA0091-3367380102

Dessart, L. (2018). Do ads that tell a story always perform better? The role of character identification and character type in storytelling ads. International Journal of Research in Marketing, 35(2), 289-304. doi: https://doi.org/10.1016/j.ijresmar.2017.12.009

Escalas, J. E. (2007). Self-referencing and persuasion: Narrative transportation versus analytical elaboration. Journal of Consumer Research, 33, 421-429. doi: 10.1086/510216

Etienne, C., \& Vanbaelen, S. (2006). Paving the way to literary analysis through TV commercials. Foreign Language Annals, 39, 87-98. doi: https://doi.org/10.1111/j.1944-9720.2006.tb02251.x

Freedman, K., \& Wood, J. (1999). Reconsidering critical response: Student judgments of purpose, interpretation, and relationships in visual culture. Studies in Art Education, 40, 128-142

Fornell, C., \& Larcker, D. F. (1981). Evaluating Structural Equation Models with Unobservable Variables and Measurement Error. Journal of Marketing Research, 18(1), 39-50. doi: 10.2307/3151312

Gottschall, J. (2012). The storytelling animal: How stories make us human. Boston, MA: Houghton Mifflin Harcourt Publishing Company.

Green, M. Clark, J. (2012). Transportation into narrative worlds: implications for entertainment media influences on tobaco use. Society for Study of Addiction, 108, 477-484. doi: 10.1111/j.13600443.2012.04088.x

Green, M., \& Brock, T. (2000). The Role of Transportation in the Persuasiveness of Public Narrative. Journal of personality and social psychology, 79, 701-721. doi: 10.1037/0022-3514.79.5.701

Hair, J., Hult, G., Ringle, C., \& Sarstedt, M. (2016). A Primer on Partial Least Squares Structural Equation Modeling (PLS-SEM): SAGE Publications.

Hair, J., Risher, J., Sarstedt, M., \& Ringle, C. (2018). When to use and how to report the results of PLS-SEM. European Business Review, 31. doi: 10.1108/EBR-11-2018-0203

Hartnett, R. (2006). Small business, big opportunity. Melbourne: Sensis.

Henseler, J., Ringle, C. M., \& Sarstedt, M. (2015). A new criterion for assessing discriminant validity in variance-based structural equation modeling. Journal of the Academy of Marketing Science, 43(1), 115-135. doi: 10.1007/s11747-014-0403-8

Hosany, S., Buzova, D., \& Sanz-Blas, S. (2020). The Influence of Place Attachment, Ad-Evoked Positive Affect, and Motivation on Intention to Visit: Imagination Proclivity as a Moderator. Journal of Travel Research, 59(3), 477-495. doi: 10.1177/0047287519830789

King, K. P. (2002). Identifying success in online teacher education and professional development. The Internet \& Higher Education, 5(3), 231. doi: 10.1016/S1096-7516(02)00104-5 
Kim, J.-E., Lloyd, S., \& Cervellon, M.-C. (2016). Narrative-transportation storylines in luxury brand advertising: Motivating consumer engagement. Journal of Business Research, 69(1), 304-313. doi: https://doi.org/10.1016/j.jbusres.2015.08.002

Lee, S., Jeong, M., \& Oh, H. (2018). Enhancing customers' positive responses: Applying sensory marketing to the hotel website. Journal of Global Scholars of Marketing Science, 28(1), 68-85. doi: 10.1080/21639159.2017.1410772

Lien, N.-H., \& Chen, Y.-L. (2013). Narrative ads: The effect of argument strength and story format. Journal of Business Research, 66(4), 516-522. doi: https://doi.org/10.1016/j.jbusres.2011.12.016

Maroco, J. (2014). Análise Estatística com o SPSS. 6ª Edição. Pêro Pinheiro: Report Number.

Martin, E. (2012). Using Advertising to Explore French Language and Culture in the Classroom. Global Business Languages, 17 (13), 161-175

Martin, E. (2006). Marketing Identities through Language. London: Palgrave Macmillan

McCurry, D. S. (2002). Multimedia case-based support of experiential teacher education: Critical self reflection and dialogue in multi-cultural contexts. Paper presented at the Annual Meeting of the American Educational Research Association, New Orleans, LA.

Moyer-Gusé, E., \& Nabi, R. L. (2010). Explaining the Effects of Narrative in an Entertainment Television Program: Overcoming Resistance to Persuasion. Human Communication Research, 36(1), 26-52. doi: 10.1111/j.1468-2958.2009.01367.x

Rajagopal, A. (2006). Brand excellence: Measuring the impact of advertising and brand personality on buying decisions. Measuring Business Excellence, 10(3), 56-65. doi: https://doi.org/10.1108/13683040610685793

Rozendaal, E., Buijzen, M. \& Valkenburg, P. M. (2012). Think-aloud process superior to thought-listing in increasing children's critical processing of advertising. Human Communication Research, 38(2), 199-221. doi: https://doi.org/10.1111/j.1468-2958.2011.01425.x

Ryu, K., Lehto, X. Y., Gordon, S. E., \& Fu, X. (2019). Effect of a brand story structure on narrative transportation and perceived brand image of luxury hotels. Tourism Management, 71, 348-363. doi: https://doi.org/10.1016/j.tourman.2018.10.021

Scheibe, C., \& Rogow, F. (2012). The teacher's guide to media literacy. Thousand Oaks, CA: Corwin

Schreiner, C., Appel, M., Isberner, M.-B., \& Richter, T. (2018). Argument Strength and the Persuasiveness of Stories. Discourse Processes, 55(4), 371-386. doi: 10.1080/0163853X.2016.1257406

Schweitzer, F., \& Van den Hende, E. A. (2017). Drivers and Consequences of Narrative Transportation: Understanding the Role of Stories and Domain-Specific Skills in Improving Radically New Products. Journal of Product Innovation Management, 34(1), 101-118. doi: 10.1111/jpim.12329

Stuckey, M., Heering, P., Mamlok-Naaman, R., Hofstein, A. \& Eilks, I. (2015). The philosophical works of Ludwik Fleck and their potential meaning for teaching and learning science. Science \& Education, 24(3), 281-298. doi: 10.1007/s11191-014-9723-9

van Laer, T., de Ruyter, K., Visconti, L. M., \& Wetzels, M. (2014). The extended transportation-imagery model: A meta-analysis of the antecedents and consequences of consumers' narrative transportation. Journal of Consumer Research, 40(5), 797-817. doi: 10.2139/ssrn.2033192

Vaughn, L. A., Childs, K. E., Maschinski, C., Paul Niño, N., \& Ellsworth, R. (2010). Regulatory Fit, Processing Fluency, and Narrative Persuasion. Social and Personality Psychology Compass, 4(12), 1181-1192. doi: 10.1111/j.1751-9004.2010.00325.x

Villani, S. (2001). Impact of media on children and adolescents: A 10-year review of the research. Journal of the American Academy of Child and Adolescent Psychiatry, 40, 392-401. doi:

https://doi.org/10.1097/00004583-200104000-00007 